\title{
HUBUNGAN ANTARA BAHAYA FISIK LINGKUNGAN KERJA DAN BEBAN KERJA DENGAN TINGKAT KELELAHAN PADA PEKERJA DI DIVISI STAMPING PT. X INDONESIA
}

\author{
Taufiq Ihsan ${ }^{1}$ dan Indah Rachmatiah S. Salami ${ }^{2}$ \\ ${ }^{1}$ Jurusan Teknik Lingkungan Fakultas Teknik Universitas Andalas \\ ${ }^{2}$ Jurusan Teknik Lingkungan Fakultas Teknik Sipil dan Lingkungan ITB \\ Email: taufiqihsan@ft.unand.ac.id
}

\begin{abstract}
ABSTRAK
Berbagai masalah kesehatan telah diketahui dari bahaya fisik lingkungan kerja dan beban kerja. PT. $X$ sebagai industri besar dunia dalam perakitan mobil termasuk di Indonesia, masih menggunakan aktivitas fisik dalam melaksanakan produksinya, khususnya di kawasan pabrik. Tuntutan produktivitas dan permintaan pasar yang tinggi, PT.X ikut meningkatkan beban kerja pada karyawannya. Selain itu juga mengembangkan penggunaan teknologi yang berpotensi munculnya bahaya fisik seperti kebisingan dan panas di lingkungan kerja. Hal ini berpotensi besar mempengaruhi terjadinya kelelahan kerja. Penelitian ini bertujuan untuk melihat hubungan tingkat kelelahan pekerja dengan bahaya fisik di lingkungan kerja dan beban kerja di Divisi Stamping. Pengukuran kelelahan kerja dilakukan dengan menggunakan alat ukur waktu reaksi (reaction timer) dan alat ukur denyut nadi. Pengukuran dilakukan pada responden pekerja selama dua minggu berturut-turut. Berdasarkan hasil pengukuran rerata waktu reaksi untuk pekerja adalah 296,28 $\pm 36,06$ milidetik dan pengukuran denyut nadi rata-rata pekerja adalah 76,7 \pm 3,03 kali per menit. Hasil analisis statistik diperoleh adanya hubungan antara kelelahan kerja dengan bahaya fisik lingkungan kerja $(p=0,000)$ dan adanya hubungan antara kelelahan kerja dengan beban kerja $(p=0,000)$ di Divisi Stamping PT.X
\end{abstract}

Kata kunci: PT. X, lingkungan kerja, temperatur, kebisingan, kelelahan kerja

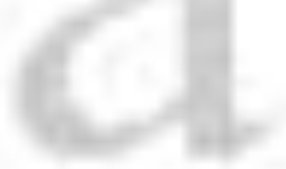

\section{ABSTRACT}

Various health problems have been identified from the physical hazards of work environment and workload. PT. X as a major industry in the world, including car assembly in Indonesia, still use physical activity in carrying out of production, particularly in the plant area. High of productivity and market demands, PT.X participate increasing workload on employees. It also developed the use of technology that has the potential emergence of physical hazards such as noise and heat in the work environment. This potentially affects the occurrence of fatigue. This study aims to look at the relationship level of worker fatigue with physical hazards in the work environment and workload in Stamping Division. Fatigue measurement performed using measuring devices reaction time (reaction timer) and measuring the pulse. Measurements conducted on respondents workers for two weeks in a row. Based on the measurement results mean reaction time is 296,28 $\pm 36,06$ milliseconds and measurement of the average pulse 76,7 $\pm 3,03$ times per minute. The results obtained by statistical analysis of the relationship between physical fatigue with workplace hazards $(p=0,000)$ and the relationship between job burnout and work load $(p=0.000)$ in Division Stamping PT.X

Keywords: PT. X, work environment, temperature, noise, fatigue 


\section{PENDAHULUAN}

Survey di negara maju melaporkan bahwa $10-50 \%$ penduduk mengalami kelelahan. Prevalensi kelelahan sekitar $20 \%$ diantara pasien yang datang membutuhkan pelayanan kesehatan (Desyariani, 2008). Data dari ILO menyebutkan hampir setiap tahun sebanyak dua juta pekerja meninggal dunia karena kecelakaan kerja yang disebabkan oleh faktor kelelahan (Putri,2008).

Berdasarkan data Dirjen Pembinaan Pengawasan Ketenagakerjaan mengenai kecelakaan kerja yang terjadi di Indonesia setiap hari rata-rata terjadi 414 kecelakaan kerja. Dimana 27,8\% disebabkan kelelahan yang cukup tinggi. Lebih kurang $9,5 \%$ atau 39 orang mengalami cacat (Hariyati, 2009).

PT. X sebagai brand industri dunia dalam perakitan mobil memiliki pabrik yang khusus memproduksi mobil untuk kawasan Asia Tenggara, berlokasi di Kawasan Industri Sunter, Jakarta Utara Indonesia. Salah satu unit produksinya adalah Divisi Stamping, tempat pembuatan dan perakitan komponen mesin di PT. X. Peningkatan produktivitas dan tingginya permintaan pasar, maka diperlukan peningkatan beban kerja dan pengembangan teknologi yang bisa menimbulkan bahaya fisik di lingkungan kerja. Beban kerja dan bahaya fisik di lingkungan kerja dapat berpotensi menimbulkan kelelahan dan gangguan kesehatan pada pekerja (Hariyati, 2009).

PT.X yang merupakan industri besar yang terus berkembang, tentu membutuhkan pekerja dengan tingkat kesehatan yang optimal Karena sebab itulah, hubungan antara kelelahan kerja dengan bahaya fisik lingkungan kerja dan beban kerja di Divisi Stamping PT. X menjadi menarik untuk diteliti.

\section{METODOLOGI}

Pengumpulan data dalam penelitian ini meliputi data sekunder dan data primer. Data sekunder berupa profil perusahaan, jumlah karyawan, jam kerja karyawan, data pengukuran kebisingan dan temperatur lingkungan kerja di Divisi Stamping PT.X.
Sementara itu, data primer berupa observasi di lapangan terkait prosedur standar produksi pabrik, pengukuran waktu reaksi dan pengukuran denyut nadi dan perhitungan beban kerja para pekerja. Sampel yang digunakan dalam pengumpulan data primer adalah pekerja tetap di Divisi Stamping. Kelompok sampel ini berjumlah 30 orang. Adapun kriteria sampel yang akan diambil adalah pekerja yang telah bekerja minimal 2 tahun, berjenis kelamin laki-laki dengan rentang usia 20-40 tahun (Sofrina, 2004).

Pengukuran kelelahan kerja berdasarkan waktu reaksi dengan menggunakan alat reaction timer seri L.77 (Gambar 1). Pelaksanaan pengukuran dilaksanakan setelah jadwal kerja berakhir dengan pengulangan sebanyak $20 \mathrm{kali}$, dimana data yang akan digunakan adalah 10 hasil pengukuran di tengah. Kegiatan ini dilakukan selama dua minggu selama 5 hari kerja yakni dari hari Senin hingga hari Jum'at. Dari hasil pengukuran ini diperoleh data berupa waktu reaksi, dimana semakin besar nilai waktu reaksi berarti adanya perlambatan proses faal syaraf dan otot. Waktu reaksi tergantung dari stimuli yang dibuat, intensitas lamanya rangsangan dan umur objek penelitian (Adiwinata, 2011). Hasil rerata tersebut dibandingkan dengan standar pengukuran kelelahan pada Tabel 1

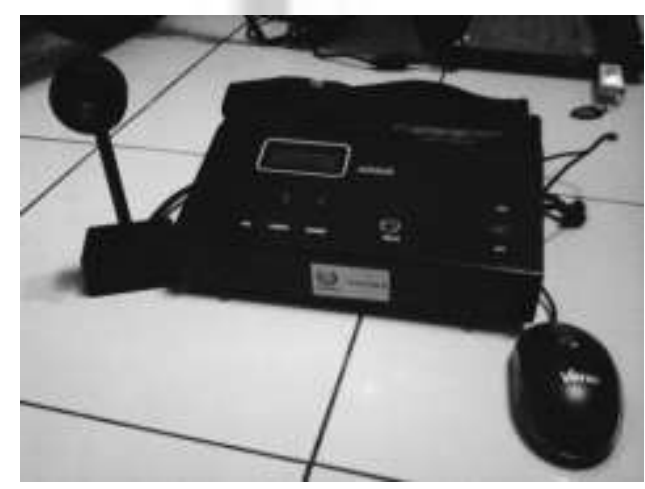

Gambar 1 Alat Ukur Waktu Reaksi

Pengukuran terhadap kondisi kesehatan pekerja dengan mengukur denyut nadi dilaksanakan setelah bekerja dengan menggunakan tensimeter digital Omron (Gambar 2). Data ini nantinya tidak hanya akan memberikan gambaran kondisi kesehatan pekerja saat menerima paparan 
bahaya fisik lingkungan kerja tapi juga bisa menjadi tolak ukur berat ringannya beban kerja fisik dan mental (Kodrat, 2009). Pengukuran juga dilakukan sejalan dengan pengukuran waktu reaksi para pekerja yang menjadi sampel dalam penelitian ini.

Tabel 1. Tingkat Kelelahan Kerja Berdasarkan Waktu Reaksi

\begin{tabular}{cc}
\hline Tingkat Kelelahan & $\begin{array}{c}\text { Waktu Reaksi } \\
\text { (mili detik) }\end{array}$ \\
\hline Normal & $150-240$ \\
Kelelahan Kerja Ringan (KKR) & $>240-<410$ \\
Kelelahan Kerja Sedang (KKS) & $>410-<580$ \\
Kelelahan Kerja Berat (KKB) & $>580$ \\
\hline
\end{tabular}

(Sumber: Tarwaka dkk, 2004)

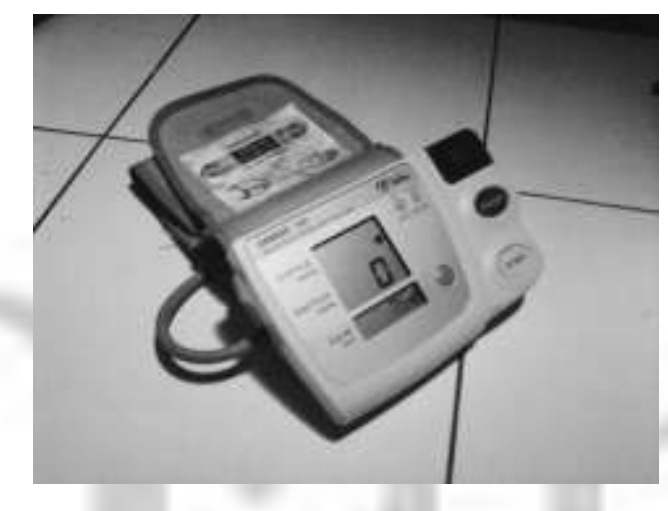

Gambar 2 Alat Pengukur Tensi

Perhitungan beban kerja berdasarkan tingkat kebutuhan kalori menurut pengeluaran energi mengacu kepada SNI 7269: 2009. Data-data yang diperlukan dalam perhitungan beban kerja antara lain berat badan pekerja, hasil pengamatan aktivitas pekerja (kategori jenis pekerjaan dan posisi badan) dan waktu aktivitas pekerja. Perhitungan rerata beban kerja sesuai Persamaan 1 dan total beban kerja sesuai Persamaan.2.

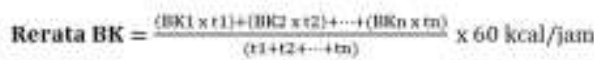

MB untuk laki-laki = berat badan dalam $\mathrm{kg} \mathrm{x}$ $1 \mathrm{kcal} / \mathrm{jam}$

MB untuk wanita $=$ berat badan dalam $\mathrm{kg} \mathrm{x}$ $0,9 \mathrm{kcal} / \mathrm{jam}$

Total BK = Rerata BK + metabolisme basal (MB)....

Di mana, $\mathrm{BK}=$ beban kerja (per jam);
$\mathrm{BK} 1, \mathrm{BK} 2, \ldots, \mathrm{BKn}=$ beban kerja $1,2, \ldots, \mathrm{n}$

(menit);

$\mathrm{T}=$ waktu (menit);

$\mathrm{t} 1, \mathrm{t} 2, \ldots, \mathrm{tn}=$ waktu sesuai aktivitas pekerja

$1,2, \ldots, \mathrm{n}$ (menit);

$\mathrm{MB}=$ metabolisme basal.

Data kebisingan, temperatur, pengukuran kelelahan, denyut nadi dan beban kerja akan dilakukan analisis statistik korelasi. Hasil analisis ini akan memperlihatkan hubungan antara kelelahan kerja dengan beban kerja dan bahaya fisik di lingkungan kerja.

Perhitungan korelasi ini akan menggunakan software SPSS v.20. Tujuan perhitungan untuk melihat pengaruh bahaya fisik di lingkungan kerja dan beban kerja yang berbeda terhadap perubahan waktu reaksi yang menjadi indikator kelelahan. Rerata variabel atribut dikatakan terdapat perbedaan yang nyata, apabila $p$-value lebih kecil dari $0,05(\mathrm{p}<0,05)$ (Dahlan, 2009)

\section{HASIL DAN PEMBAHASAN}

Sampel dalam penelitian ini adalah pekerja laki-laki dengan status karyawan tetap di Divisi Stamping PT.X. Karakteristik usia pekerja yang menjadi sampel penelitian dapat dilihat pada Gambar 3. Hampir sebagian besar sampel berada pada rentang usia muda yakni 21 - 25 tahun $(60 \%)$.

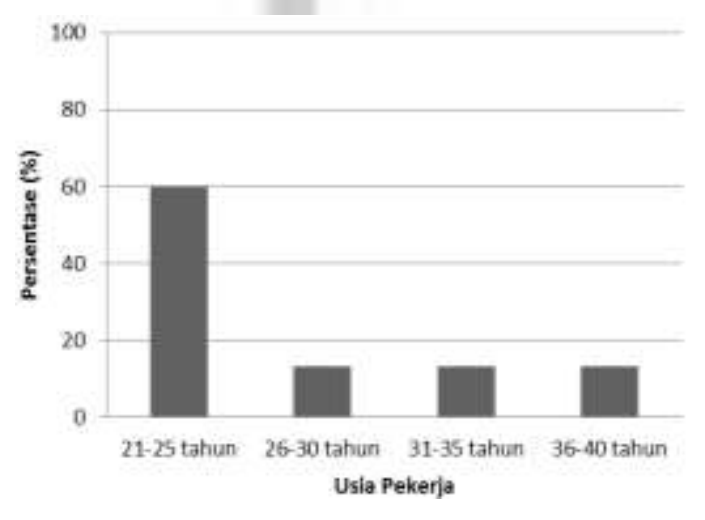

Gambar 3 Karakteristik Usia Sampel

Pada pabrik PT. X untuk menjadi karyawan tetap, berlaku kontrak 2 tahun terlebih daulu. Oleh karena itu dalam penelitian ini dilakukan pemilihan sampel berupa pekerja yang telah menjadi karyawan tetap pada Divisi Stamping ini. Para pekerja pabrik yang menjadi sampel hampir sebagian besar 
mempunyai pengalaman kerja kurang dari 5 (lima) tahun, yaitu sebesar 53,33\%. Ini dapat dilihat persentasenya pada Gambar 4 berikut.

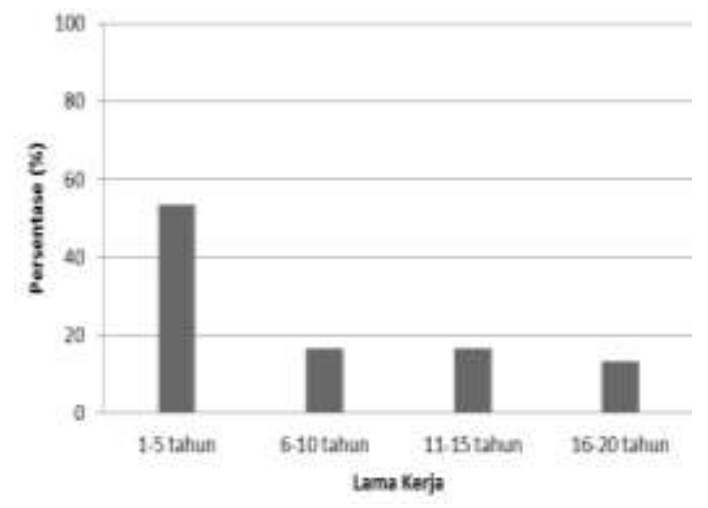

Gambar 4 Lama Kerja Sampel di Divisi Stamping PT.X

Pembagian jumlah sampel berdasarkan line kerja diusahakan seimbang dan sesuai dengan jumlah karyawan untuk tiap line kerja. Line kerja yang berbeda aktivitas diharapkan nantinya akan memperlihatkan beban kerja yang harus ditanggung pekerja tiap line. Divisi Stamping PT. X mempunyai 7 line kerja. Sebaran sampel penelitian pada line kerja dapat dilihat pada Gambar 5.

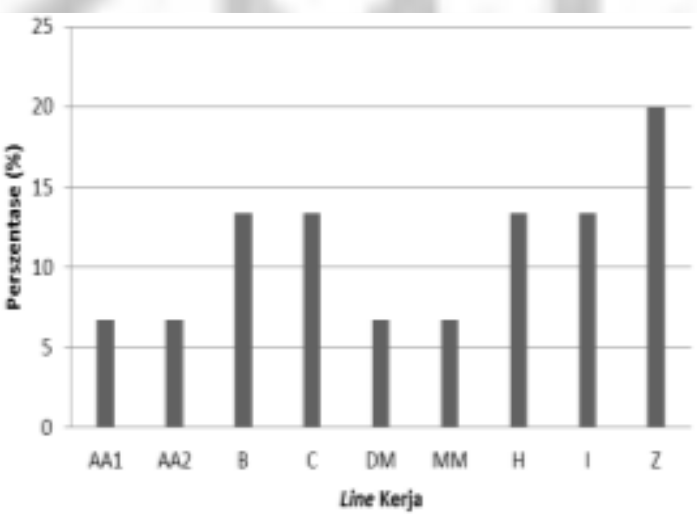

Gambar 5. Persentase Sebaran Sampel di tiap Line Kerja PT. X

Hasil pengukuran di lapangan, diperoleh bahwa rerata kalori beban kerja berdasarkan SNI 7269: 2009 untuk tujuh line kerja, tergolong kategori beban kerja sedang, yang membutuhkan kalori untuk pengeluaran energi lebih besar dari $200-350 \mathrm{kkal} / \mathrm{jam}$. Sementara itu, untuk line DM (Dies Maintenance) dan MM (Machine
Maintenance), maka beban kerjanya termasuk kategori beban kerja ringan, yang membutuhkan kalori untuk pengeluaran energi sebesar 100 sampai dengan 200 $\mathrm{kkal} / \mathrm{jam}$.

Bahaya fisik yang diterima responden saat bekerja di Divisi Stamping adalah berupa temperatur dan kebisingan. Potensi bahaya fisik ini berasal dari mesin-mesin yang beroperasi \pm 24 jam, dan letak antar mesin yang tergolong berdekatan antar line kerja. Rekapitulasi kalori beban kerja antar line kerja dan hasil pengukuran temperatur dan kebisingan dapat dilihat pada Tabel 2 .

Evaluasi temperatur di lingkungan kerja berdasarkan Keputusan Menteri Kesehatan Republik Indonesia Nomor 1405/MENKES/2002 tentang Persyaratan Kesehatan Lingkungan Kerja Perkantoran dan Industri. Temperatur pada ruangan di industri berkisar antara $18-30^{\circ} \mathrm{C}$. Pada penelitian ini, dapat dilihat, hanya line $\mathrm{DM}$ dan MM saja yang memiliki temperatur berada di rentang aman. Tujuh line sisanya memiliki temperatur lingkungan kerja di atas $30^{\circ} \mathrm{C}$. Temperatur lingkungan kerja yang tinggi bisa berpotensi menimbulkan dehidrasi pada pekerja, yang berujung pada kelelahan dan kecelakaan kerja (Adiwinata,2011).

Tabel 2. Rekapitulasi Bahaya Fisik Lingkungan Kerja dan Kalori Beban Kerja di Divisi Stamping PT. X

\begin{tabular}{|c|c|c|c|}
\hline \multirow{2}{*}{ Line } & \multicolumn{2}{|c|}{$\begin{array}{c}\text { Bahaya Fisik } \\
\text { Lingkungan Kerja }\end{array}$} & \multirow{2}{*}{$\begin{array}{c}\text { Beban } \\
\text { Kerja } \\
\text { (kkal/jam) }\end{array}$} \\
\hline & $\begin{array}{c}\text { Temperatur } \\
\left({ }^{\mathrm{O}} \mathbf{C}\right)\end{array}$ & $\begin{array}{l}\text { Kebisingan } \\
(\text { dB })\end{array}$ & \\
\hline AA1 & 31,90 & 101,75 & 282,84 \\
\hline AA2 & 31,18 & 100,61 & 279,83 \\
\hline B & 32,22 & 94,04 & 284,78 \\
\hline C & 32,66 & 94,11 & 280,29 \\
\hline DM & 25,50 & 79,20 & 174,36 \\
\hline $\mathbf{H}$ & 32,24 & 97,36 & 210,18 \\
\hline I & 32,48 & 97,84 & 284,78 \\
\hline MM & 25,50 & 75,98 & 194,56 \\
\hline $\mathbf{Z}$ & 31,29 & 97,50 & 278,07 \\
\hline
\end{tabular}

Kebisingan di Divisi Stamping dibandingkan dengan nilai ambang batas berdasarkan Keputusan Menteri No. 51/MEN/1999, 
yakni sebesar 85 dB. Menurut Tabel 2, terlihat bahwa line DM dan MM memiliki nilai kebisingan sebesar 79,20 dB dan 75,98 $\mathrm{dB}$, yang berarti dibawah nilai ambang batas. Untuk 7 line lainnya memiliki nilai di atas ambang batas kebisingan. Kebisingan yang tinggi terjadi pada 7 line kerja Divisi Stamping diakibatkan oleh hentakan dan kekuatan mesin-mesin yang posisinya berdekatan, saat melakukan press dan ini dioperasikan hampir 24 jam. Berbeda dengan line DM dan MM yang tidak terlalu berhubungan dengan mesin. Adanya tingkat kebisingan yang tinggi, bukan hanya menyebabkan terjadinya pergeseran dan penurunan batas pendengaran bagi pekerja, tapi juga berdampak kepada fisiologis dan psikologis. Dampak yang diberikan ini cenderung mengarah kepada penurunan produktivitas kerja yang berujung kepada kelelahan kerja (Bahar, 2008).

Hasil pengukuran kelelahan kerja dilihat dari waktu reaksi sampel, diperoleh bahwa rerata waktu reaksi adalah 296,28 milidetik dengan standar deviasi 36,06 milidetik. Menurut standar tingkat kelelahan berdasarkan waktu reaksi, ini berarti tergolong kategori kelelahan kerja ringan. Kelelahan kerja ringan memiliki waktu reaksi antara 240 hingga 410 milidetik.

Menurut analisis statistik dengan kruskall wallis test diketahui $p$-value untuk parameter usia responden terhadap waktu reaksi adalah $0,004(\mathrm{p}<0,05)$. Hal ini berarti rerata waktu reaksi berdasarkan kelompok usia pekerja dalam penelitian ini berbeda secara nyata. Semakin tua umur seseorang semakin besar tingkat kelelahan. Semakin berumur, maka akan mengalami penurunan kekuatan otot yang berdampak terhadap kelelahan dalam melakukan pekerjaan (Maurits, 2008).

Berdasarkan hasil analisis statistik dengan kruskall wallis test untuk parameter lama kerja responden terhadap waktu reaksi, diperoleh $p$-value sebesar 0,0394 $(\mathrm{p}<0,05)$. Hal ini menandakan nilai rerata waktu reaksi menurut kelompok lama kerja berbeda secara nyata. Lama kerja akan memberikan pengaruh negatif apabila semakin lama bekerja akan menimbulkan kelelahan dan kebosanan serta semakin banyak dia telah terpapar bahaya yang ditimbulkan oleh lingkungan kerja tersebut (Budiono, 2003).

Menurut hasil analisis statistik diperoleh $p$ value untuk parameter line kerja terhadap waktu reaksi dengan kruskall wallis test adalah $0,043(\mathrm{p}<0,05)$. Hal ini berarti nilai rerata waktu reaksi antar line kerja di Divisi Stamping berbeda secara nyata. Perbedaan antara line kerja terlihat dari kalori beban kerja yang dialami oleh responden. Beban kerja yang terlalu berlebihan akan menimbulkan kelelahan baik fisik atau mental dan reaksi-reaksi emosional seperti sakit kepala, gangguan pencernaan dan mudah marah. Bukan hanya itu saja, pengulangan gerak dalam jangka waktu yang lama akan menimbulkan kebosanan dan rasa monoton, yang berujung kepada kurangnya perhatian pada pekerjaan secara potensial (Simanjuntak, 2010).

Berdasarkan hasil analisis statistik wilcoxon test diperoleh $p$-value untuk hubungan antara waktu reaksi dengan temperatur sebesar 0,000 $(p<0,05)$, yang berarti terdapat pengaruh yang signifikan antara temperatur lingkungan kerja dengan waktu reaksi pekerja. Sedangkan $p$-value untuk hubungan antara waktu reaksi dengan kebisingan sebesar $0,000(\mathrm{p}<0,05)$, yang berarti juga terdapat pengaruh nyata antara kebisingan lingkungan kerja dengan waktu reaksi pekerja.

Menurut Guyton (1991, dalam Ramdan, 2007), akibat suhu lingkungan yang tinggi, suhu tubuh akan meningkat. Akibatnya hipotalamus merangsang kelenjar keringat sehingga tubuh mengeluarkan keringat, yang mengandung garam natrium chlorida. Keluarnya garam natrium chlorida bersama keringat akan mengurangi kadarnya dalam tubuh, sehingga menghambat transportasi glukosa sebagai sumber energi. Hal ini menyebabkan penurunan kontraksi otot sehingga tubuh mengalami kelelahan.

Tenaga kerja yang terpapar kebisingan denyut nadinya akan naik, tekanan darah naik, dan mempersempit pembuluh darah sehingga cepat merasa lelah. Kebisingan mengganggu konsentrasi, komunikasi, dan kemampuan berpikir (Bahar, 2008). 
Pengukuran denyut nadi diperoleh rerata 76,7 kali per menit dengan standar deviasi 3,03 kali per menit. Berdasarkan analisis statistik dengan mann-whitney test untuk jumlah denyut nadi dengan kebisingan dan temperatur lingkungan kerja, diperoleh $p$ value sebesar $0,000(\mathrm{p}<0,05)$, yang berarti terdapat perbedaan rerata jumlah denyut nadi akibat kebisingan dan temperatur ruangan.

Jumlah denyut nadi per menit yang dirasakan oleh pekerja akan mempengaruhi kegiatan pekerja saat beraktivitas, karena peningkatan denyut nadi akan mengakibatkan penyempitan pembuluh darah dan semakin terkurasnya energi dalam menyelesaikan pekerjaan, sehingga merangsang untuk menjadi cepat lelah (Hariyati, 2009).

\section{SIMPULAN}

PT. X sebagai industri mobil terbesar dunia, memiliki pabrik perakitan di Indonesia. Salah satu unit produksi PT.X adalah Divisi Stamping yang memiliki 7 (tujuh) line kerja, dengan kondisi lingkungan kerja dan beban kerja yang berbeda.

Pengukuran kelelahan dilakukan dengan menggunakan reaction timer dan pengukuran denyut nadi pekerja setelah bekerja. Hasil pengukuran dikaitkan dengan data pengukuran kebisingan dan temperatur lingkungan kerja dan beban kerja tiap line kerja.

Berdasarkan hasil analisis korelasi statistik pada penelitian ini menunjukkan adanya hubungan yang signifikan antara kelelahan kerja dengan usia pekerja, lama kerja, beban kerja dan bahaya fisik lingkungan kerja. Hal ini dibtandai dengan $p$-value kurang dari $0,05(\mathrm{p}<0,05)$.

\section{DAFTAR PUSTAKA}

Adiwinata, G.E. 2011. Analisis Resiko Kesehatan Paparan Panas terhadap Dehidrasi dan Kelelahan pada Pekerja di Industri Tekstil PT.X. Tesis Program Studi Teknik Lingkungan. FTSL-ITB, Bandung

Bahar, A. 2008. Analisis Resiko Kesehatan terhadap Paparan Bising di
Lingkungan Kerja Departemen

Tempa dan Cor PT. X Tesis Program Studi Teknik Lingkungan FTSL-ITB, Bandung

Budiono, AM. 2003. Bunga Rampai Hiperkes dan KK. Badan Penerbit UNDIP, Surabaya

Dahlan, M.S. 2009. Statistik untuk Kedokteran dan Kesehatan, Edisi 4. Salemba Medika, Jakarta

Desyariani, V. 2008. Hubungan Waktu Tempuh dan Over Time dengan Frekuensi Kelelahan pada Pengemudi Truk Mixer PT.X tahun 2008. Skripsi FKM-UI, Depok, Universitas Indonesia

Hariyati, M. 2009. Pengaruh Beban Kerja terhadap Kelelahan Kerja pada Pekerja Linting Manual di PT. Djitoe Indonesia Jakarta. Skripsi FK-USM, Surakarta

Keputusan Menteri Kesehatan Republik Indonesia Nomor : 1405/MENKES/SK/XI/2002 tentang Persyaratan Kesehatan Lingkungan Kerja Perkantoran dan Industri

Keputusan Menteri Tenaga Kerja Nomor : Kep-51/MEN/1999 tentang Nilai Ambang Batas Faktor Fisika di Tempat Kerja

Kodrat, Kimberley Febrina. 2009. Pengaruh Shift Kerja terhadap Kelelahan Pekerja Pabrik Kelapa Sawit di PT. X, Jurnal Teknik Industri 12(2), 110117. Kesehatan Masyarakat. USU, Medan Maurits, L, Imam DW. 2008. Faktor dan Penjadwalan Shift Kerja, Jurnal Teknoin 13(20:11-22). Yogyakarta

Putri, D. 2008. Hubungan Faktor Internal dan Eksternal Pekerja terhadap Kelelahan pada Operator Alat Besar PT. Indonesia Power Unit Bisnis Pembangkit Suralaya tahun 2008. Skripsi FKM-UI, Depok. Universitas Indonesia

Ramdan, I. 2007. Dampak Giliran Kerja, Suhu dan Kebisingan terhadap Perasaan Kelelahan Kerja di PT LJP Provinsi Kalimantan Timur, The Indonesian Journal of Public Health,4(1): 8-13

Simanjuntak, R. 2010. Analisa Pengaruh Shift Kerja terhadap Beban Kerja Mental, Jurnal Teknologi 3:53-60 
Institut Sains \& Teknologi AKPRIND, Yogyakarta

SNI 7269 (2009) : Penilaian Beban Kerja

Berdasarkan Tingkat Kebutuhan Kalori Menurut Pengeluaran Energi, Badan Standardisasi Nasional
Sofrina, I. 2004. Analisis Hubungan Kerja Gilir dengan Tingkatan Stress pada Pekerja Laki-laki di Pabrik Semen X Jawa Barat. Tesis Program Studi Kedokteran Kerja. FK-UI, Jakarta

Tarwaka, Solichul, B.; Lilik S. 2004. Ergonomi untuk Kesehatan Kerja dan Produktivitas. UNIBA Press, Surakarta 